\title{
Genetic Divergence Studies in Pearl Millet Germplasm Based on Principal Component Analysis
}

\author{
Om Vir Singh", R. Gowthami, Kartar Singh and Neelam Shekhawat
}

ICAR-National Bureau of Plant Genetic Resources Regional Station, Jodhpur-342003, India

*Corresponding author

\begin{tabular}{|l|}
\hline Ke y w o r d s \\
$\begin{array}{l}\text { Pearl millet, Principal } \\
\text { component analysis, } \\
\text { Multivariate analysis }\end{array}$ \\
\hline Article Info \\
\hline $\begin{array}{l}\text { Accepted: } \\
\text { 04 May } 2018 \\
\text { Available Online: } \\
\text { 10 June } 2018\end{array}$ \\
\hline
\end{tabular}

A B S T R A C T

A total of 40 germplasm representing central arid zone were evaluated for five consecutive years during Kharif season at research field of ICAR-NBPGR, regional station, Jodhpur. PCA analysis revealed that the first six components in the PCA analysis were with Eigen values more than one and contributed to a maximum of 78.29 per cent of the variability among 40 genotypes evaluated for thirteen different morphological traits). Days to flowering, days to maturity, reproductive period, number of productive tillers per plant, spike girth test, weight and single plant yield, were the characters contributing positively to the second principal component (PC 2) accounting for 15.13 per cent of the variability explained. The third component, accounts for 11.42 per cent of total variability is a measure of single plant yield and revealed that higher plant yields are obtained with a reduction in the number of days to fifty percent flowering and days to maturity and the fourth component, accounting for 10.43 per cent of total variability and characters like test weight, number of productive tillers per plant, spike girth and stover yield contributed in positive way. The fifth component accounting 10.43 per cent of the total variability and the sixth component had high loadings for number of productive tillers per plant followed by spike length, spike girth, ear exertion distance, single plant yield and stover yield contributing 5.03 per cent of the total variability. In all the six components traits like number of productive tillers per plant, spike girth and single plant yield and in few cases traits like plant height, spike length and test weight contributed positively to the total variation. Hence these traits can be used for selection in crop breeding programmes in pearl millet.

\section{Introduction}

Pearl millet [Pennisetum glaucum (L.) R. Br. emend Stanz] is one of the coarse grain crop provides food, feed and fodder for people and animals. Pearl mille is one of the kharif season crop of arid and semi-arid regions and plays a major role in livelihood improvement due to a high degree of climatic adaptability and can be grown in dry lands and poor soils. As India is characterized by environmental vagaries and varied rainfall pattern may lead to the conditions of terminal stress during grain formation period. Therefore, the grain yields are greatly depending on the ability of the varieties to mature before the exhaustion of soil moisture. For development of superior hybrids and varieties, assessment of nature 
and extent of genetic variation available among the parental lines is essential.

Pearl millet is endowed with a rich reservoir of genetic variability for various yield components, quality traits, biotic and abiotic stress tolerant traits (Berwal and Khairwal, 1997). Exploitation of this genetic variability in the breeding programme of pearl millet is very much essential. Selection of parents is the most important step in any crop improvement programmes (Islam, 2004). The more diverse the parents, the greater are the chances of obtaining new genes combinations which in turn helps in crop improvement and to meet the present production challenges (Berwal and Khairwal, 1997).

Scientists used several measures to assess genetic diversity among plant populations. Among these measures, multivariate analysis provides the most reliable information. Among the multivariable procedures, PCA (Principal Component Analysis) has an edge over the other as it removes multicollinearity among the independent variables. Principal component analysis (PCA) reflects the importance of the largest contributor to the total variation at each axis of differentiation. Principal component analysis being a data reduction technique for investigating the interdependence attempts to simplify complex and diverse relationships existing among a set of observed variables, by revealing common dimensions or components that link seemingly unrelated variables. Hence an attempt has been made to perform the diversity analysis in pearl millet germplasm for grain yield and its associating characters.

\section{Materials and Methods}

Forty national elite pearl millet germplasm including checks conserved at regional seed gene bank of ICAR-NBPGR, regional station, Jodhpur were evaluated in the present study.
The experimental trial was laid out in randomized block design with three replications for five consecutive years (environments) viz., Kharif 2012, Kharif 2013, kahrif 2014, Kharif 2015 and Kharif 2016 at Research field of NBPGR, Regional station, Jodhpur, India, which is situated at about $28^{0}$ $35^{\prime} \mathrm{N}$, longitude of $70^{\circ} 18^{\prime} \mathrm{E}$ and an altitude of $226 \mathrm{~m}$ above mean sea level. The recommended agronomic packages of practices were followed during the experimental period. Thirteen morphological traits were recorded on five randomly selected plants of each accession as per the standard descriptors. The thirteen traits are as follows: days to fifty per cent flowering (DFF), days to maturity (DTM), Reproductive period (RP), plant height $(\mathrm{PH})$, number of productive tillers per plant (NPT), number of leaves per plant (NLP), spike length (SL), spike girth (SG), ear exertion distance (EED), test weight (TW), stover yield (SY), single plant yield (SPY) and harvest index (HI). The data were subjected to PCA was performed using the statistical package SPSS 16.0 version. Principal component analyses (PCA) based on 13 quantitative traits for pooled data were performed to find out the relative importance of different traits in capturing the variation in germplasm.

\section{Results and Discussion}

Principal Component Analysis was applied as a reductionist approach of the multivariate data, to measure the importance and contribution of each component to total variance. PCA provides information on the independent impact of a particular trait to the total variance, wherein each coefficient of Eigen vectors indicates the degree of contribution of every original variable, with which each principal component is associated. PCA analysis revealed that the first six components in the PCA analysis were with Eigen values more than one and contributed to 
a maximum of 78.29 per cent of the variability among 40 genotypes evaluated for thirteen different morphological traits. These five principal components were retained based on the screen plot and threshold Eigen value greater than 1 (Fig. 1 and Table 1). All the traits in first component (PC1) contributing in a positive direction except reproductive period and ear exertion distance and the characters plant height, number of productive tillers per plant, spike length, test weight, stover yield, single plant yield and harvest index are the major characters of plant morphological and grain yield contributing traits contributed maximum 33.92 per cent variability to the first principal component (PC 1) (Table 2 and Fig. 2) indicating that the high yielding lines were differentiated on the basis of these characters. Similar trend using PC analysis in pearl millet for the traits grain yield and plant height was reported by Bhattacharjee et al., (2002), Yadav et al., (2013). Occurrence of both positive and negative loading in a single component shows the presence of positive and negative correlation trends between the components and the variables. Hence, these characters which load high positively or negatively contributed more to the diversity (Bhanupriya et al., 2014).

Days to flowering, days to maturity, reproductive period, number of productive tillers per plant, spike girth test, weight and single plant yield, were the characters contributing positively to the second principal component (PC 2) accounting for 15.13 per cent of the variability explained. This shows that increased seed size (bolder seeds), late flowering, late maturity plants had less number of productive tillers, poor growth rate and less panicle weight (Chaudhary, 2005).

This indicated that tall accessions tend to produce very low number of tillers as reported by Geethanjali and Jegadeeswaran (2016) and Upadhayay et al., (2009) in Foxtail millet.

Table.1 Eigen value and percent of total variation for various principal components

\begin{tabular}{|l|c|c|c|}
\hline Component & Eigen value & Variance explained (\%) & Cumulative (\%) \\
\hline $\mathbf{1}$ & 5.843 & 33.925 & 33.922 \\
\hline $\mathbf{2}$ & 2.148 & 15.137 & 46.753 \\
\hline $\mathbf{3}$ & 1.975 & 11.542 & 55.32 \\
\hline $\mathbf{4}$ & 1.523 & 10.438 & 62.975 \\
\hline $\mathbf{5}$ & 1.237 & 7.104 & 70.754 \\
\hline $\mathbf{6}$ & 1.165 & 5.035 & 78.295 \\
\hline $\mathbf{7}$ & 0.749 & 4.623 & 83.652 \\
\hline $\mathbf{8}$ & 0.631 & 3.221 & 87.938 \\
\hline $\mathbf{9}$ & 0.557 & 2.982 & 91.146 \\
\hline $\mathbf{1 0}$ & 0.324 & 2.012 & 95.653 \\
\hline $\mathbf{1 1}$ & 0.182 & 1.543 & 97.568 \\
\hline $\mathbf{1 2}$ & 0.106 & 0.987 & 99.349 \\
\hline $\mathbf{1 3}$ & 0.082 & 0.015 & 99.633 \\
\hline $\mathbf{1 4}$ & 0.032 & 0.01 & 99.982 \\
\hline $\mathbf{1 5}$ & 0.0001 & 0.0005 & 100 \\
\hline
\end{tabular}


Table.2 Factor loadings of thirteen characters with respect to different PC's (Principal components)

\begin{tabular}{|l|}
\hline Characters \\
\hline Days to fifty percent flowering \\
\hline Days to maturity \\
\hline Reproductive period \\
\hline Plant height \\
\hline No. of productive tillers per plant \\
\hline No. of leaves per plant \\
\hline Ear exertion distance \\
\hline Spike length \\
\hline Spike girth \\
\hline Test weight \\
\hline Stover yield per plant \\
\hline Single plant yield \\
\hline Harvest index \\
\hline
\end{tabular}

\begin{tabular}{|l|l|l|l|l|l|}
\hline \multicolumn{1}{|c|}{$\mathbf{1}$} & \multicolumn{1}{|c|}{$\mathbf{2}$} & \multicolumn{1}{|c|}{$\mathbf{3}$} & \multicolumn{1}{|c|}{$\mathbf{5}$} & \multicolumn{1}{|c|}{$\mathbf{6}$} \\
\hline 0.058 & -0.232 & -0.265 & -0.143 & -0.102 & -0.018 \\
\hline 0.061 & -0.225 & -0.286 & -0.132 & -0.103 & -0.164 \\
\hline-0.045 & 0.143 & -0.237 & -0.286 & -0.315 & -0.613 \\
\hline 0.216 & -0.115 & 0.102 & -0.086 & 0.073 & -0.034 \\
\hline 0.231 & 0.351 & 0.158 & 0.458 & 0.118 & 0.302 \\
\hline 0.054 & -0.027 & 0.013 & 0.123 & -0.204 & -0.242 \\
\hline 0.115 & 0.034 & 0.253 & -0.105 & -0.032 & 0.183 \\
\hline 0.028 & 0.232 & 0.187 & 0.283 & 0.526 & 0.261 \\
\hline-0.035 & -0.027 & 0.047 & -0.154 & 0.043 & 0.109 \\
\hline 0.108 & 0.315 & -0.212 & 0.336 & 0.115 & -0.312 \\
\hline 0.132 & -0.057 & -0.102 & 0.157 & 0.117 & 0.086 \\
\hline 0.155 & 0.324 & 0.425 & 0.243 & 0.132 & 0.104 \\
\hline 0.138 & -0.087 & -0.052 & -0.032 & -0.022 & -0.085 \\
\hline
\end{tabular}

Fig.1 Scree plot showing the Eigen value variation for thirteen quantitative traits in pearlmillet

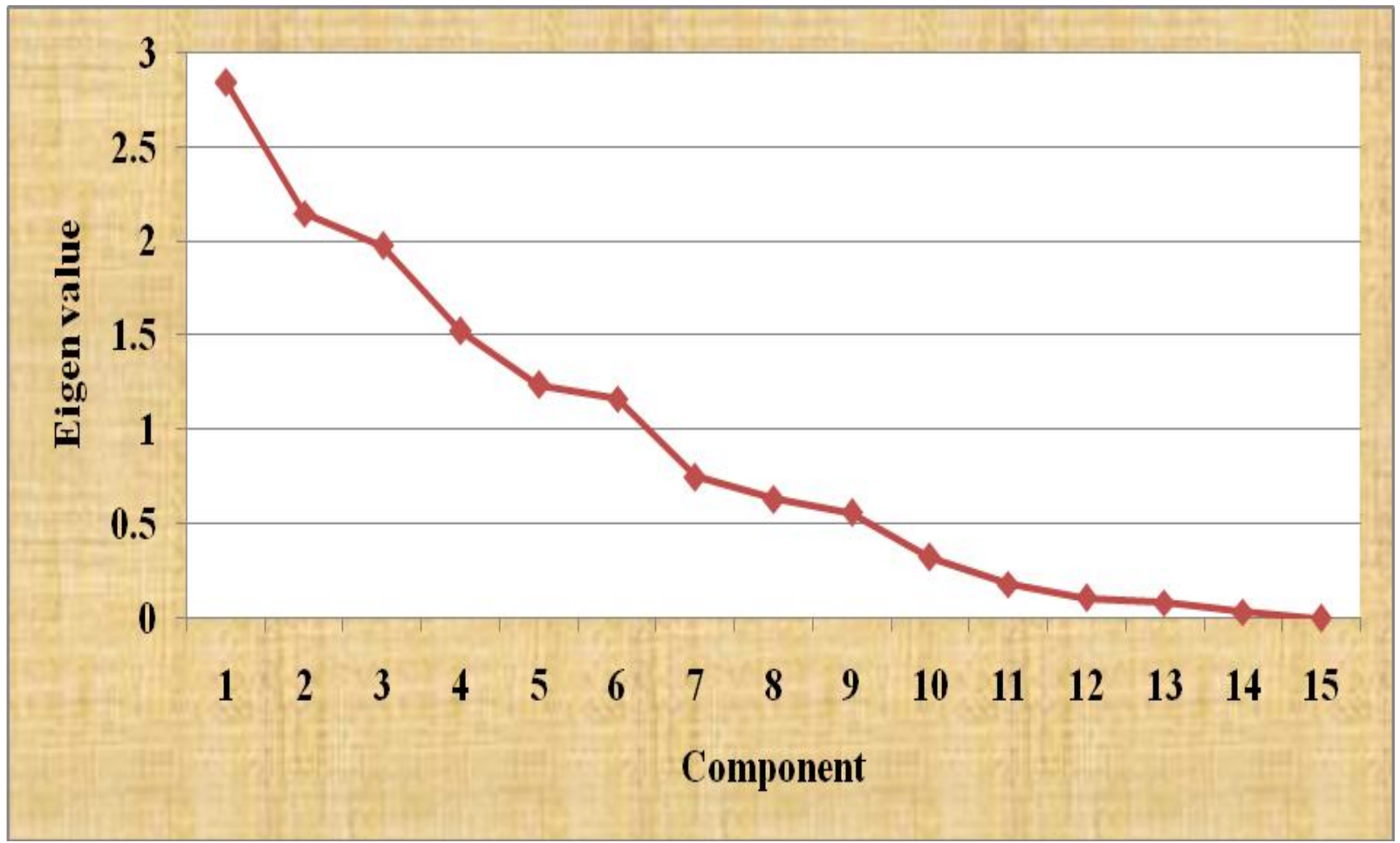


Fig.2 Factor loadings of thirteen characters with respect to different PC's (Principal components)

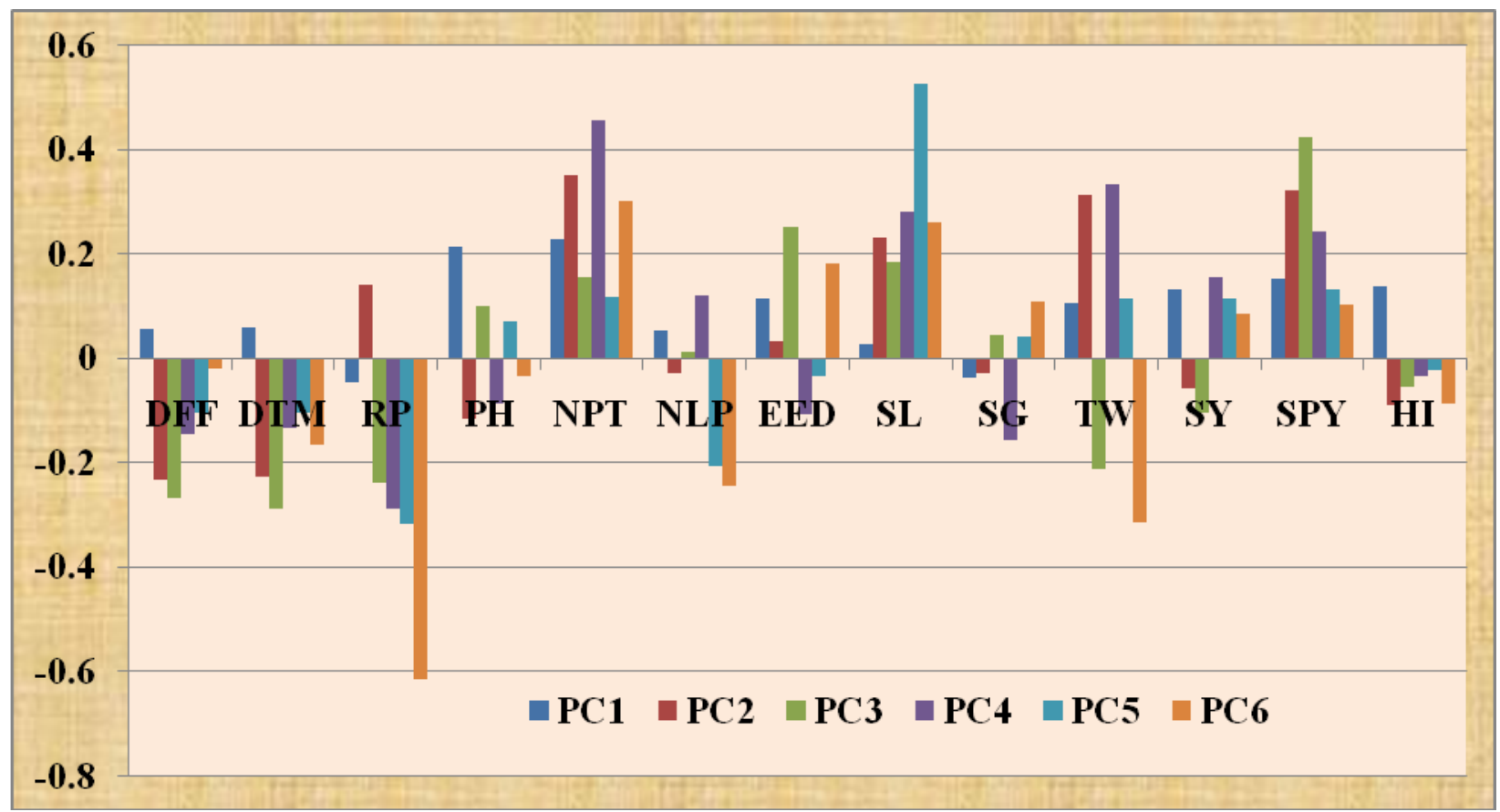

The third component, accounts for 11.42 per cent of total variability is a measure of single plant yield. At the same time, PC3 revealed that higher plant yields are obtained with a reduction in the number of days to fifty percent flowering and days to maturity, this shows that crop can escape from the drought or water shortage. The fourth component, accounting for 10.43 per cent of total variability and characters like test weight, number of productive tillers per plant, spike girth and stover yield contributed in positive way. Increased number of productive tillers per plant was found to increase test weight and single plant yield. The fifth component had high loadings for spike girth accounting for 10.43 per cent of the total variability. An increase in spike girth had a positive effect on number of productive tillers per plant, test weight, single plant yield and stover yield. Loadings of the fifth component indicated that with an increase in spike girth there is an increase in number of grains per panicle, seed density and seed filling accounting a positive increase in single plant yield. The sixth component had high loadings for number of productive tillers per plant followed by spike length, spike girth, ear exertion distance, single plant yield and stover yield contributing 5.03 per cent of the total variability. The prominent characters identified in a particular principal component as prime contributors to total variability have the tendency to hang together and can be used effectively for selection in crop breeding programmes. In all the six components traits like number of productive tillers per plant, spike girth and single plant yield and in few cases traits like plant height, spike length and test weight contributed positively to the total variation. Hence these traits can be used for selection in crop breeding programmes in pearl millet.

\section{References}

Berwal, K.K and I.S. Khairwal, (1997). Genetic divergence in Pearl millet. International Sorghum and Millet Newsletter, 38, pp103-106. 
Bhanupriya, B. Das, N.H. Satyanarayana, S. Mukherjee and K. K. Sarkar. 2014. Genetic diversity of wheat genotypes based on principal component analysis in Gangetic alluvial soil of West Bengal. Journal of Crop and Weed, 10(2):104-107.

Bhattacharjee, Ranjana, P. J. Bramel, C. T. Hash, M. A. Kolesnikova-Allen, and I. S. Khairwal, 2002: Assessment of genetic diversity within and between pearl millet landraces. Theor. Appl. Genet., 105: 666-673.

Chaudhary, Sunita. 2005: Genotypic variation for starch, protein, seed yield and its attributes in pearl millet. Unpubl. M. Sc. thesis submitted to CCSHAU, Hisar.

Geethanjali, S and M. Jegadeeswaran. 2016. Genetic diversity and variability in Foxtail millet [Setaria italica (L.)] germplasm based on morphological traits. Electronic Journal of Plant Breeding, Vol 7(2): 303-316.

Islam, M. R. 2004. Genetic diversity in irrigated rice. Pak. J. Biol. Sci., 2: 22629.

Upadhyaya, H. D., Pundir, R.P.S., Dwivedi, S. L and Gowda, C. L. L. 2009. Mini Core Collections for Efficient Utilization of Plant Genetic Resources in Crop Improvement Programs. Information Bulletin No. 78. Patancheru 502 324, Andhra Pradesh, India: International Crops Research Institute for the Semi-Arid Tropics. 52 pp.

Yadav, Ashok Kumar, M. S. Narwal, and Rajesh Kumar Arya. 2013: Evaluation of pearl millet (Pennisetum glaucum) genotypes and validation of screening methods for supra-optimal temperature tolerance of seedling stage. Indian $J$ agric. Sci., 83: 260- 271.

\section{How to cite this article:}

Om Vir Singh, R. Gowthami, Kartar Singh and Neelam Shekhawat. 2018. Genetic Divergence Studies in Pearl Millet Germplasm Based on Principal Component Analysis. Int.J.Curr.Microbiol.App.Sci. 7(06): 522-527. doi: https://doi.org/10.20546/ijcmas.2018.706.059 